\title{
Is it time to move up? Feasibility of medical abortion between 9-13 weeks of gestation
}

\author{
Vandana Jha $^{1}$, Ayesha ${ }^{1}$, Subrat Panda ${ }^{2}$, Rina Sharma ${ }^{1}$
}

\begin{abstract}
${ }^{1}$ Department of Obstetrics and Gynaecology, Mayo Institute of Medical Sciences, Lucknow, Uttar Pradesh, India ${ }^{2}$ Department of Obstetrics and Gynaecology, North Eastern Indira Regional Institute of Medical Sciences, Shillong, Meghalaya, India
\end{abstract}

Received: 17 July 2016

Accepted: 09 August 2016

\author{
*Correspondence: \\ Dr. Vandana Jha, \\ E-mail: vandanajhakm@gmail.com
}

Copyright: $(\odot$ the author(s), publisher and licensee Medip Academy. This is an open-access article distributed under the terms of the Creative Commons Attribution Non-Commercial License, which permits unrestricted non-commercial use, distribution, and reproduction in any medium, provided the original work is properly cited.

\begin{abstract}
Background: Medical termination of pregnancy act helps to reduce incidence of illegal abortion its dreaded complication like maternal mortality to analyze the safety, efficacy and acceptability of medical regimen in 9-13 weeks of pregnancy.

Methods: A prospective study was carried out for a period of two and half years. All patients between 9-13 weeks of pregnancy seeking medical termination of pregnancy were given either medical regimen or surgical abortion depending on patients' preference. Medical regimen consisted of $200 \mathrm{mg}$ of mifepristone followed by $600 \mathrm{mcg}$ of misoprostol after 48 hours. If required 2nd and 3rd dose of misoprostol was repeated. Surgical abortion was done under sedation after cervical priming with misoprostol.

Results: Out of 353 cases of medical termination of pregnancy, 92 cases (26.1\%) were between 9-13 weeks of pregnancy. Two cases were excluded as surgical abortion was indicated in them. Out of 90 cases, only 30 cases (33.3\%) were willing to participate in randomized controlled trial if needed. Out of 90 cases, $50(55.6 \%)$ preferred surgical abortion, while $40(44.4 \%)$ cases preferred medical abortion. Out of 40 cases of medical abortion, 5\% cases required surgical curettage, while $3.8 \%$ cases required repeat curettage in surgical group. Minor complication rate was comparable in both groups except for prolonged bleeding, which was significantly higher in medical abortion group. Major complication in the surgical group was uterine perforation (1.9\%). After completion of procedure, both group satisfied with same procedure, $92 \%$ in medical abortion group and $89 \%$ in surgical abortion group.

Conclusions: Medical abortion is a safe and effective alternative to surgical abortion between 9-13 weeks of gestation. It should be included routinely at these gestations, thus increasing women's choice. However randomized controlled trial for medical versus surgical abortion between 9-13 weeks will be difficult to initiate.
\end{abstract}

Keywords: Mifepristone, Misoprostol, Medical abortion, Surgical abortion

\section{INTRODUCTION}

Medical termination of pregnancy act helps to reduce incidence of illegal abortion its dreaded complication like maternal mortality. In our institute 353 cases of medical termination of pregnancy was done between in a period of two years. Out of which $92(26.1 \%)$ cases was between 9-13 weeks of pregnancy. According to FOGSI guideline up to 9 weeks patient may have choice of surgical and medical abortion both. At present surgical abortion is the only available choice between 9-13 weeks where complications of surgical abortion is highest. Some inter- 
national study shows that medical regimen can be used between 9-13 weeks, although Indian data are waiting. Medical abortion regimen for early medical abortion consists of mifepristone followed by misoprostol.

Mifepristone is a steroid compound, which competes with progesterone at the receptor level and is widely used for first and second trimester termination of pregnancy. ${ }^{1,2}$

Mifepristone, administered before misoprostol, increases the sensitivity of the uterus to prostaglandins and ripens the cervix, thereby allowing lower doses of misoprostol to induce expulsion of the fetus.

\section{METHODS}

To see safety, efficacy and acceptability of medical regimen as compared to surgical abortion in between 913 weeks of pregnancy. To see feasibility of starting a randomized control trial for evaluating the same.

\section{Study design}

This was a prospective study designed to carry out in a period of two and half years. Women seeking for termination of pregnancy at 9-13 weeks amenorrhoea, and fulfilling the requirements of the 1971 MTP Act, were taken as study subjects.

The exclusion criteria were: (I) Ultrasonographically confirmed gestation of more than 13 weeks or less than 9 weeks (ii) suspected ectopic pregnancy; (iii) chronic adrenal failure; (iv) long term corticosteroid treatment; (v) Haemorrhagic disorder and treatment with anticoagulants; (v) known allergy to mifepristone; (vi) twin or higher order gestation .

101 Cases of 9-13 weeks pregnancy seeking for medical termination of pregnancy was counselled by the attending resident after sonography, out of which 2 cases not came for repeat visit and, 3 cases decided to continue pregnancy, while 2 cases shows missed abortion on sonography, one cases shows on sonography gestation $<7$ weeks and one shows twin gestation. Remaining 92 cases counselled regarding the method, known complication, hospital stay required in both surgical and medical method. With informed choice, following questionnaire were used before starting of procedure.

- Which method you will prefer?

- If either surgical or medical method will be chosen by a lottery system, will you willing to accept?

Both surgical and medical method cases were admitted as indoor cases.

In medical methods groups on day one $200 \mathrm{mg}$ mifepristone was given on day one with patient admitted in ward, 600 microgram (mcg) misoprostol was given after 48 hours per vaginally and earlier if bleeding started, second and third dose of misoprostol (400 mcg) if required repeated orally every four hourly. It is consider as failure if curettage needed due to heavy bleeding, sonography at discharge or after two weeks shows retained product or patient heaving persistent bleeding for which ultimately curettage needed. Follow-up scheduled visit was after two weeks.

In surgical group, 400 microgram misoprostol was inserted per vaginally, after 4-6 hours surgical evacuation done under local anaesthesia, patient was discharged on next day with advice of follow -up visit after two weeks or earlier if required. Curettage was done by attending resident on duty.

In both group routine analgesic was given consisting of $500 \mathrm{mg}$ paracetamol given thrice a day for first 2 days and after that instructed to take on demand and report the same during schedule visit.

In both group routine antibiotic of azithromycin $1000 \mathrm{mg}$ was given (as routine testing of Chlamydia is not feasible in our set -up) and metronidazole $400 \mathrm{mg} 2$ tab per rectally given at the time of procedure.

A type of outcome measures after medical termination of pregnancy was divided in two groups.

\section{Primary outcomes measured was}

- Recommendation of methods, if needed for second time or you will advise other people

- Efficacy of both methods-efficacy of the procedure was defined as complete uterine evacuation without the need for a second procedure (subsequent surgical re curettage or medical regimen).

\section{Secondary outcomes}

- Pain resulting from the procedure, reported by the women or measured by use of analgesics

- Side effects such as pyrexia, nausea, vomiting and diarrhoea

- Uterine rupture

- Infectious morbidity

- Mortality.

\section{RESULTS}

Out of 92 cases, 2 cases were on corticosteroid, so surgical method recommended. Remaining 90 cases, only 30 cases were agreed to participate in randomized study if needed, other 60 cases denied taking chance. As our study design, 40 cases preferred medical abortion, while 50 cases preferred surgical abortion.

Only 8 cases were primigravida, out of which 6 preferred medical abortions, as they were unwilling for any 
invasive procedure. Reason for preference for medical abortion was those cases who underwent earlier surgical abortion with improper sedation and analgesia.

General characteristic of both groups is compared with respect to period of gestation, age, gravida, history of previous induced abortion. Mean period of gestation was 10.9 and 10.46 weeks respectively in medical and surgical abortion groups with no significant difference. Ages of women undergoing participation in medical and surgical groups no significant difference. Out of 8 primigravida 6 cases opted medical abortion while 2 cases opted surgical abortion (Table 1).

Out of 90 cases, $56 \%$ cases opted for surgical abortion, while $44 \%$ cases opted for medical abortion. Major reasons for opting surgical abortion was age old method and one step method while major reason for opting medical abortion was avoiding surgical intervention (Table 2).

Table 1: General characteristic of study subjects.

\begin{tabular}{|lllll|}
\hline Group & $\begin{array}{l}\text { Period of gestation (POG) } \\
\text { Mean (s.d) }\end{array}$ & Age Mean (s.d) & $\begin{array}{l}\text { Primigravida } \\
\text { Medical abortion group (40) }\end{array}$ & $\begin{array}{l}\text { Previous induced } \\
\text { abortion }\end{array}$ \\
\hline Surgical abortion group (52) & $10.9(0.9)$ & $25.6(5)$ & $6(15 \%)$ & $9(22.5 \%)$ \\
\hline P value & Not significant & $26.9(4.6)$ & $2(3.8 \%)$ & $15(28.8 \%)$ \\
\hline
\end{tabular}

Table 2: Trends for preference of methods of MTP.

\begin{tabular}{|lll|}
\hline Group preference & cases & $(\%)$ \\
\hline Surgical abortion & 50 & 55.6 \\
\hline Medical abortion & 40 & 44.4 \\
\hline Total & 90 & 100 \\
\hline
\end{tabular}

Table 3: Feasibility of conducting Randomized controlled trial (RCT) for medical versus surgical abortion.

\begin{tabular}{|lll|}
\hline Group & Cases & $(\%)$ \\
\hline Willing to participate in RCT & 30 & $33.4 \%$ \\
\hline Not willing to participate in RCT & 60 & $66.7 \%$ \\
\hline Total & 90 & 100 \\
\hline
\end{tabular}

When we asked women to participate in randomised control trial by lottery method. $66.7 \%$ of women denied taking chance. Due to this it seems difficult to RCT for medical versus surgical abortion (Table 3).
Medical abortion group recommended same method for future if needed in $60 \%$ cases, while surgical abortion group recommended same in $88 \%$ if needed. So primary outcome was patient satisfaction which was more in medical abortion group (Table 4).

Table 4: Primary outcome measured in two groups.

\begin{tabular}{|ll|}
\hline Study groups & $\begin{array}{l}\text { Recommendation of same } \\
\text { methods in future }\end{array}$ \\
\hline Medical group (40) & $37(92.5 \%)$ \\
\hline Surgical group (52) & $46(88.46 \%)$ \\
\hline
\end{tabular}

Table 5: Efficacy of abortion method according to gestation.

\begin{tabular}{|lll|}
\hline Group & $\begin{array}{l}\text { Medical } \\
\text { abortion }\end{array}$ & $\begin{array}{l}\text { Surgical } \\
\text { abortion }\end{array}$ \\
\hline Complete abortion & $38(95 \%)$ & $50(96.2 \%)$ \\
\hline Re-curettage rate & $2(5 \%)$ & $2(3.8 \%)$ \\
\hline Total & $40(100 \%)$ & $52(100 \%)$ \\
\hline
\end{tabular}

Table 6: Other secondary outcome measured.

\begin{tabular}{|c|c|c|c|c|}
\hline Complications & Medical group & Surgical group & P value & stat \\
\hline Pain (additional analgesic used) & $1.9(0.47)$ & $1.6(0.32)$ & ns & t- test \\
\hline Days of vaginal bleeding & $\begin{array}{l}14.21(4.2) \\
\text { Mean (s. d.) }\end{array}$ & $\begin{array}{l}9(5.1) \\
\text { Mean (s. d.) }\end{array}$ & $<0.05$ & t- test \\
\hline Infection rate & 1 & 2 & ns & Chi-square \\
\hline Minor side effect & $18(45 \%)$ & $22(42.3)$ & ns & Chi-square \\
\hline Uterine rupture / perforation & 0 & $1(1.9 \%)$ & ns & Chi-square \\
\hline
\end{tabular}


Table 7: Some others factors regarding medical abortion.

\begin{tabular}{|llll|}
\hline $\begin{array}{l}\text { No of cases } \\
\text { bleeding started }\end{array}$ & $\begin{array}{l}<4 \\
\text { hours }\end{array}$ & $\begin{array}{l}24-36 \\
\text { hours }\end{array}$ & $36-48$ \\
\hline & 0 & 2 & 8 \\
\hline
\end{tabular}

Efficacy of medical abortion method was $95 \%$ as compared to $96 \%$ efficacy of surgical method (Table 5).

Mean quantity of analgesic used was more in medical group as compared to surgical group. Mean number of days of vaginal bleeding was 14.21 days in medical abortion groups and 9 days in surgical abortion group, but difference was not significant statistically. Minor side effects consist of nausea, vomiting, diarrhoea, dizziness during indoor admission or patient revisited for the same. Infection rate was not significantly different in two groups. 1 case of uterine perforation was noted in surgical abortion group, this is the major morbidity associated with surgical abortion (Table 6).

Out of 40 cases participated in medical abortion, 10 cases have bleeding only with mifepristone (Table 7).

Dose of misoprostol required range from (0-3) with median of 2 . The mean time interval from administration of mifepristone to prostaglandin administration was 42.80 h (range 31.8-49.1).

\section{DISCUSSION}

A majority $(90 \%)$ of the terminations take place in the first trimester. Worldwide mid-trimester abortion constitutes $10-15 \%$ of all induced abortions but is responsible for two-thirds of all major complications. ${ }^{3}$

We have used mifepristone $200 \mathrm{mg}$. This standard dose is comparable with other study. The approved dose of mifepristone in medical mid-trimester abortion is $600 \mathrm{mg}$ (similar to early medical abortion), but it has been shown that the abortion rate and induction-to- abortion interval were the same even if the dose was reduced to $200 \mathrm{mg}^{4}$

Around $0.2-0.4 \%$ of women aborts with mifepristone only. ${ }^{5,6}$ Although in our cases no patient aborted with mifepristone only, bleeding started with use of mifepristone in 10 cases.

Vaginal bleeding was more common in medical abortion group in our study with $\mathrm{p}$ value significant. Due to vaginal bleeding more revisit to clinician was seen in our study, this is similar to previous study. The rate of consultations related to a diagnosis of hemorrhage was eight times more common following medical termination of pregnancy. As medical abortion is associated with uterine bleeding lasting approximately two weeks (Spitz et al), the high rate of consultations is not surprising. ${ }^{7}$
In our study $67 \%$ women have preference to particular method, which is comparable to study by Ashok et al, where $80 \%$ of women had a definite preference for a particular method, of these, the majority preferred the medical method, of those who underwent medical abortion, $70 \%$ would opt for the same method in future while $79 \%$ who underwent vacuum aspiration would opt for the same in future-a statistically significant difference. This is different from our study reason being we have given the treatment according to patient's preference. ${ }^{8}$

According to ashok et al, medical abortion is as safe and effective as vacuum aspiration at 10-13 weeks gestation. Our study shows also efficacy of medical and surgical method is comparable with no statistically significant difference. $^{8}$

Efficacy of medical method is $95 \%$ in our study which makes medical abortion in later first trimester an effective alternative of surgical method of abortion. Schaff and colleagues also showed no difference in efficacy in relation to gestation, with medical abortion being highly acceptable $(91 \%) .^{9}$ There are some limitations of the study although prospective not randomized so patient preferred bias may influence the acceptability of minor side effect.

\section{CONCLUSION}

Medical abortion is a safe and effective alternative to surgical abortion between 9-13 weeks of gestation. It should be included routinely at these gestations, thus increasing women's choice. However randomized controlled trial for medical versus surgical abortion between 9-13 weeks will be difficult to initiate.

\section{ACKNOWLEDGEMENTS}

We acknowledge all patients participated in study.

Funding: No funding sources

Conflict of interest: None declared

Ethical approval: The study was approved by the Institutional Ethics Committee NEIC/74/2012

\section{REFERENCES}

1. Newhall EP, Winikof B. Abortion with mifepristone and misoprostol: Regimens, efficacy, acceptability and future directions. Am J Obstet Gynecol. 2000;182:44-53.

2. El-Refaey H, Rajasekar D, Abdalla M, Calder L, Templeton A. Induction of abortion with mifepristone (RU 486) and oral or vaginal misoprostol. N Engl J Med. 1995;332:983-7.

3. World Health Organization. Medical Methods for Termination of Pregnancy. WHO Technical Report Series 871. World Health Organization, Geneva. 1997. 
4. Webster D, Penney GC, Templeton A. A comparison of 600 and $200 \mathrm{mg}$ mifepristone prior to second trimester abortion with the prostaglandin misoprostol. Br J Obstet Gynaecol. 1997;103:706-9.

5. UK Multicenter Study Group. Oral mifepristone 600 $\mathrm{mg}$ and vaginal gemeprost for mid-trimester induction of abortion. An open multicenter study. Contraception. 1997;56:361-6.

6. Tang OS, Thong KJ and Baird DT. Second trimester medical abortion with mifepristone and gemeprost: a review of 956 cases. Contraception. 2001;64:29-32.

7. Spitz IM, Bardin CW, Benton L, Robbins A. Early pregnancy termination with mifepristone and misoprostol in the United States. N Engl J. 1998;338(18):1241-7.

8. Ashok PW, Kidd A, Flett GM, Fitzmaurice A, Graham W, Templeton A. A randomized comparison of medical abortion and surgical vacuum aspiration at 10-13 weeks gestation. Hum Reprod. 2002;17:928.

9. Schaff EA, Fielding SL, Eisinger SH. Low-dose mifepristone followed by vaginal misoprostol at 48 hours for abortion up to 63 days. Contraception. 2000;61:41-6.

Cite this article as: Jha V, Ayesha, Panda S, Sharma R. Is it time to move up? Feasibility of medical abortion between 9-13 weeks of gestation. Int J Reprod Contracept Obstet Gynecol 2016;5:3121-5. 